6. Jabbarpour Y, Westfall J. Diversity in the family medicine workforce. Fam Med. 2021;53(7):640-643. 10.22454/FamMed.2021.284957

7. Xierali IM, Nivet MA, Gaglioti AH, Liaw WR, Bazemore AW. Increasing family medicine faculty diversity still lags population trends. J Am Board Fam Med. 2017;30(1):100-103. 10.3122/jabfm.2017.01.160211

8. Coe C, Piggott C, Davis A, et al. Leadership pathways in academic family medicine: focus on underrepresented minorities and women. Fam Med. 2020;52(2):104-111

9. South-Paul J, Goodell K, Coe C, et al. Leadership development taskforce final report to CAFM. Published Dec 31, 2017. Accessed Oct 28, 2021. https:// www.aafp.org/dam/foundation/documents/Internal/workingparty/CAFM_ Leadership_Development_Taskforce.pdf

10. Weidner A, Clements DS. CAFM leadership demographics. Ann Fam Med. 2021;19(2):181-185. 10.1370/afm.2678

11. Association of American Medical Colleges. Underrepresented in medicine, definition. Accessed Oct 28, 2021. https://www.aamc.org/what-we-do/ equity-diversity-inclusion/underrepresented-in-medicine

$\because$ NAPCRG

Ann Fam Med 2022;20:98-99. https://doi.org/10.1370/afm.2778.

\section{FROM NAPCRG: PRIMARY CARE RESEARCH THROUGH THE LENS OF NAPCRG'S TRAINEE COMMITTEE: A YEAR OF REFLECTION IN A PANDEMIC AND A CALL TO ACTION}

When the world paused in 2020, ensnared in the grip of the COVID-19 pandemic, many research trainees found themselves re-examining their goals. Barriers to traditional research strategies as well as pandemic-exacerbated inequities presented new challenges and highlighted previously neglected research agendas. The NAPCRG Trainee Committee seized this opportunity to facilitate robust virtual discussions. These virtual discussions hosted diverse groups of international researchers and trainees to highlight the hurdles presented by conducting and disseminating research during a pandemic. Challenges, however, are the catalyst for change. Research provides the means to address both longstanding injustices, as well as the rapidly evolving landscape of research methodology and communication. As trainees, we are inherently focused on the future. We propose 3 critical areas where primary care researchers are the ideal leaders: seeking novel solutions to health disparities, battling mis- and disinformation, and innovating in research methodologies conducive to adapting to the new era of primary care research.

\section{A Commitment to Health Equity}

The pandemic has disproportionately impacted populations experiencing inequities globally, highlighting the need to dismantle existing barriers in health systems that perpetuate health inequities, especially racism. ${ }^{1}$ As a committee we discussed how research can perpetuate health inequities.
Through virtual discussions we have learned that tackling health equity in research is extremely complex, especially in health systems that have historically contributed to the problem. As trainees, we endeavor to be part of the solution and recognize that the status quo is no longer acceptable. To address health equity in research, we emphasize diversifying the research workforce, modeling inclusion, and amplifying researchers with diverse backgrounds and perspectives. Further, our research agendas and strategies must change, creating research objectives with health equity in mind, including patient partners with diverse backgrounds, and interrogating data and systems of data collection for bias. We challenge the primary care research community to commit to health equity and anti-racism as an integral component of research endeavors.

\section{Communicating Research Effectively}

The past year has led to an unprecedented amount of research output in a short period of time. This influx of available information bred an ever-increasing number of non-peer reviewed outlets, including social media platforms. ${ }^{2}$ While these new avenues of communication are effective mechanisms for sharing information rapidly, they have differing standards for evidence-based review and have created substantial challenges for communicating accurate and upto-date information. As the future of primary care research, we have a responsibility to modernize our communication approaches and we must lead the battle against mis- and disinformation that contribute to deaths worldwide. While this problem is not new, the proliferation of false information can be addressed by primary care researchers, building on relationships with patients and communities.

\section{A New Way of Conducting Research}

Although the pandemic has disrupted the delivery of health care, a variety of benefits emerged for primary care researchers including the development of novel methods for conducting research. ${ }^{3}$ Rapid evidence reviews, implementation science, and evaluating interventions "in-flight" became the new normal. Early in the pandemic, some clinical and research trainees felt they were left on the sidelines for safety precautions; this pause in day-to-day work opened the doors for trainees to learn from experts and avail themselves of resources that may not have been accessible previously. For example, virtual communities of practice formed that created a unique platform where trainees and experts were learning together about the new context of primary care. As a group that has primarily benefited from increased access to information and mentorship, we recommend fostering these innovations in research and incorporating them as the "new normal" in conducting research.

As trainees and the next generation of primary care researchers, we are continuously considering the future of primary care research and the skills that we will need to be successful in the field. While the past year has forced us to 
think critically about health equity, communicating research, and how we conduct research, we propose a call to action to the research community to integrate these three themes into future research projects. The past year has challenged us to conduct research differently and now we challenge you to bring these lessons into the future to strengthen primary care research for the better.

Asbley Chisholm, MSc, James Wang, MD, MAS, Levi N Bonnell, $M P H_{i}$ Elise Duwe, MD, PbD, Megban Gilfoyle, MSc, Jacqueline K. Kueper, MSc, Ione Locher, MD, Sarab Gebauer, MD, MSPH

\section{About the NAPCRG Trainee Committee}

In 2018, NAPCRG established a committee for its trainee members to give a voice to the newest members of the primary care research field. Over the past year, NAPCRG's inaugural Trainee Committee hosted a series of virtual sessions that included robust discussions with trainees and experts in the field on topical issues in primary care research.

\section{References}

1. Berkowitz SA, Cené CW, Chatterjee A. Covid-19 and health equity-time to think big. N Engl J Med. 2020;383(12):e76. 10.1056/NEJMp2021209

2. World Health Organization. Managing the COVID-19 infodemic: promoting healthy behaviours and mitigating the harm from misinformation and disinformation. Joint statement by WHO, UN, UNICEF, UNDP, UNESCO, UNAIDS, ITU, UN Global Pulse, and IFRC. Published Sep 23, 2020. https://www.who.int/ news/item/23-09-2020-managing-the-covid-19-infodemic-promoting-healthybehaviours-and-mitigating-the-harm-from-misinformation-and-disinformation

3. Scallan S, Lyon-Maris J. The educational impact of COVID-19: views from UK GP educators and trainees. Educ Prim Care. 2020;31(5):328-329. $10.1080 / 14739879.2020 .1806736$ 